\title{
Severe anaemia is associated with a higher risk for preeclampsia and poor perinatal outcomes in Kassala hospital, eastern Sudan
}

\author{
AbdelAziem A Ali', Duria A Rayis², Tajeldin M Abdallah', Mustafa I Elbashir and Ishag Adam²*
}

\begin{abstract}
Background: Anaemia during pregnancy is major health problem. There is conflicting literature regarding the association between anaemia and its severity and maternal and perinatal outcomes.

Methods: This is a retrospective case-control study conducted at Kassala hospital, eastern Sudan. Medical files of pregnant women with severe anaemia (haemoglobin $(\mathrm{Hb})<7 \mathrm{~g} / \mathrm{dl}, \mathrm{n}=303$ ) who delivered from January 2008 to December 2010 were reviewed. Socio-demographic and obstetric data were analysed and compared with a similar number of women with mild/moderate anaemia $(\mathrm{Hb}=7-10.9 \mathrm{~g} / \mathrm{dl}, \mathrm{n}=303)$ and with no anaemia $(\mathrm{Hb}>11 \mathrm{~g} / \mathrm{dl}$, $\mathrm{n}=303$ ). Logistic regression analysis was performed separately for each of the outcome measures: preeclampsia, eclampsia, preterm birth, low birth weight (LBW) and stillbirth.
\end{abstract}

Results: There were 9578 deliveries at Kassala hospital, 4012 (41.8\%) women had anaemia and 303 (3.2\%) had severe anaemia. The corrected risk for preeclampsia increased only in severe anaemia $(\mathrm{OR}=3.6,95 \% \mathrm{Cl}: 1.4-9.1, P=$ 0.007). Compared with women with no anaemia, the risk of LBW was 2.5 times higher in women with mild/ moderate anaemia (95\% Cl: 1.1-5.7), and 8.0 times higher in women with severe anaemia (95\% Cl: 3.8-16.0). The risk of preterm delivery increased significantly with the severity of anaemia $(O R=3.2$ for women with mild/moderate anaemia and $\mathrm{OR}=6.6$ for women with severe anaemia, compared with women with no anaemia). The corrected risk for stillbirth increased only in severe anaemia $(\mathrm{OR}=4.3,95 \% \mathrm{Cl}: 1.9-9.1, P<0.001)$.

Conclusions: The greater the severity of the anaemia during pregnancy, the greater the risk of preeclampsia, preterm delivery, LBW and stillbirth. Preventive measures should be undertaken to decrease the prevalence of anaemia in pregnancy.

\section{Background}

Anaemia during pregnancy is a major public health problem, especially in developing countries [1]. It affects $41.8 \%$ of pregnant women globally, with the highest prevalence in Africa [2]. There is however significant variation in the prevalence of anaemia both within and between countries, necessitating a need for local data to help to improve preventive programmes. Anaemia during pregnancy, especially severe anaemia, is associated with increased maternal morbidity and mortality and contributes to $20 \%$ of the maternal mortality in Africa $[1,3,4]$. Anaemia during pregnancy is associated with a

\footnotetext{
* Correspondence: ishagadam@hotmail.com

${ }^{2}$ Faculty of Medicine, University of Khartoum, Khartoum, Sudan

Full list of author information is available at the end of the article
}

negative impact on both the woman and neonate. Fetal anaemia, low birth weight (LBW), preterm birth and stillbirth have been associated with anaemia [4-9].

There is conflicting literature regarding the association between anaemia and perinatal outcomes. Some recent studies $[8,10]$ have demonstrated a strong association between anaemia and adverse perinatal outcomes such as preterm delivery and LBW, while other previous studies found no association [11,12]. A meta-analysis showed that anaemia during early pregnancy, but not during late pregnancy, is associated with slightly increased risk of preterm delivery and LBW [13]. Many studies have used different definitions and were undertaken in areas with a low prevalence of anaemia [13]. There is therefore insufficient information to conclusively assess the effect of maternal anaemia on maternal
C Biomed Central

(c) 2011 Adam et al; licensee BioMed Central Ltd. This is an open access article distributed under the terms of the Creative Commons Attribution License (http://creativecommons.org/licenses/by/2.0), which permits unrestricted use, distribution, and reproduction in any medium, provided the original work is properly cited. 
and perinatal outcomes. Furthermore, most studies were not able to study anaemia according to its severity.

In Kassala hospital, eastern Sudan we have recently reported a high prevalence of obstetric complications [14], high maternal mortality rate and high prevalence of anaemia including severe anaemia among pregnant women $[15,16]$. The current study was therefore conducted in Kassala hospital to investigate if severe anaemia is a risk factor for preeclampsia, eclampsia, preterm birth, LBW and stillbirth.

\section{Methods}

Kassala, eastern Sudan, is an area of $42282 \mathrm{~km}^{2}$ located nearly $600 \mathrm{~km}$ from the capital city Khartoum with a population of 1.8 million including 440491 women of reproductive age. Kassala hospital provides tertiary care for women who receive antenatal care at the hospital, as well as for referrals from other clinics and hospitals and for women who live close to the hospital facility. All women with risk factors or obstetric complications are referred to this hospital. However, the referral criteria are not strictly adhered to and many patients with no significant complications also deliver at the hospital.

The medical files of women with severe anaemia who delivered at Kassala maternity hospital during the 3 year period from January 2008 to December 2010 were retrospectively retrieved. The data of severely anaemic cases were compared with similar numbers of cases with mild/moderate anaemia with no anaemia. The control group (no anaemia) were women with file numbers following the cases of severe anaemia.

Data retrieved included socio-demographic characteristics (age, parity, residence, education and antenatal care), maternal outcomes (preterm birth, preeclampsia, eclampsia and heart failure) and neonatal outcomes (preterm birth, LBW and stillbirth). Only women with singleton pregnancies were included.

Maternal anaemia was defined when haemoglobin $(\mathrm{Hb})$ was $<11 \mathrm{~g} / \mathrm{dl}$ and was classified as mild/moderate (7-10.9 $\mathrm{g} / \mathrm{dl})$ or severe $(<7 \mathrm{~g} / \mathrm{dl})$ [1]. Preeclampsia was defined as diastolic blood pressure $\geq 90 \mathrm{mmHg}$ and/or systolic blood pressure $\geq 140 \mathrm{mmHg}$ recorded on 2 occasions 4 hours apart, plus dipstick proteinuria $\geq 2+$, after the 20th week of gestation in a previously normotensive woman.
Eclampsia, a severe complication of preeclampsia, was defined as the new onset of seizures in a woman with preeclampsia. Gestational age in weeks was calculated from the first day of the last menstrual period. Preterm delivery was defined as delivery before 37 completed weeks of gestation. LBW was defined as $<2.5 \mathrm{~kg}$. Stillbirth was defined as delivery of a dead infant after 24 weeks of gestation.

\section{Statistics}

Data were entered into a computer database using SPSS software (SPSS Inc., Chicago, IL, USA, version 16.0). Comparisons between categorical variables were made using the $\chi^{2}$ test, and between quantitative variables using the independent $t$-test or one-way ANOVA. A $P$ value of less than 0.05 was considered statistically significant. Logistic regression analysis was performed separately for preeclampsia, eclampsia, preterm birth, LBW and stillbirth to evaluate the effects of both mild/moderate and severe maternal anaemia. Odds ratios (ORs) and their corresponding 95\% confidence intervals (CIs) were calculated, using women with no anaemia as the reference category. The corrected ORs were calculated after removing the confounders in each model (age, parity, education, residence and antenatal care). Preeclampsia and eclampsia were regarded as confounders when we investigated the risk for perinatal outcomes.

\section{Ethics}

The study received ethical approval from the Health Research Board at the Ministry of Health, Kassala, Sudan.

\section{Results}

\section{Patient characteristics}

There were 9578 deliveries at Kassala hospital during the study period. Of these, $4012(41.8 \%)$ women had anaemia and $303(3.2 \%)$ had severe anaemia at the time of delivery. Age and parity were not significantly different between women with no anaemia, women with mild/moderate anaemia and women with severe anaemia. A significantly higher number of women with severe anaemia had lower antenatal care attendance, lower level of education and rural residence, table 1.

Table 1 Socio-demographic characteristics of the investigated women

\begin{tabular}{lllll}
\hline Variable & $\begin{array}{l}\text { Normal } \\
(\mathbf{N}=\mathbf{3 0 3})\end{array}$ & $\begin{array}{l}\text { Mild/moderate anaemia } \\
(\mathbf{N}=\mathbf{3 0 3})\end{array}$ & $\begin{array}{l}\text { Severe anaemia } \\
(\mathbf{N}=\mathbf{3 0 3})\end{array}$ & $\boldsymbol{P}$ \\
\hline Age, years & $32.2(6.1)$ & $33.2(5.0)$ & $33(6.0)$ & 0.1 \\
Parity & $3.2(2)$ & $3.2(2.4)$ & $3.4(2.1)$ & 0.3 \\
Rural residence & $113(37.3 \%)$ & $231(76.2 \%)$ & $246(81.2 \%)$ & 0.001 \\
lack of antenatal care & $98(32.3 \%)$ & $163(53.7 \%)$ & $229(75.5 \%)$ & $<0.001$ \\
Education < secondary level & $73(24 \%)$ & $173(57 \%)$ & $176(58 \%)$ & $<0.001$ \\
\hline
\end{tabular}


The association between anaemia and preeclampsia and eclampsia

The prevalence of preeclampsia and eclampsia was significantly higher in women with severe anaemia $(8.2 \%$ and $3.3 \%$, respectively), table 2 . The corrected risk for preeclampsia $(\mathrm{OR}=3.6,95 \% \mathrm{CI}: 1.4-9.1, P=0.007)$ increased only in severe anaemia, table 3. Logistic regression analysis showed that maternal age was also a risk factor for preeclampsia, with a higher risk in women aged $<20$ years $(\mathrm{OR}=7.6,95 \% \mathrm{CI}: 2.9-19.9)$ and in women aged $>35$ years $(\mathrm{OR}=10.2$, 95\% CI: 3.2 32.2). The risk for eclampsia was not increased in women with anaemia, table 3 . There were three maternal deaths due to heart failure in the group with severe anaemia.

The association between anaemia and perinatal outcomes Women with severe anaemia delivered infants with a significantly lower birth weight than women with mild/ moderate anaemia and women with no anaemia (mean [standard deviation] $=2.9[0.7]$ vs. $3.1[0.6]$ vs. $3.3[0.5]$ $\mathrm{kg}, P<0.001)$ and with a lower gestational age $(37.3$ [8.4] vs. $38.2[7.1]$ vs. 39.5 [6.3], $P=0.001)$. The prevalence of preterm delivery and LBW was significantly higher in women with anaemia, table 2 and increased with the severity of anaemia. Compared with women with no anaemia, the risk of LBW was 2.5 times higher (95\% CI: 1.1-5.7) in women with mild/moderate anaemia and 8.0 times higher (95\% CI: 3.8-16.0) in women with severe anaemia. Compared with women with no anaemia, the risk of preterm delivery increased significantly with the severity of anaemia (mild/moderate anaemia $\mathrm{OR}=3.2$, 95\% CI: 1.5-6.6; severe anaemia $\mathrm{OR}=6.6$, 95\% CI: 2.7-16.3), table 3. The corrected risk for stillbirth increased only in severe anaemia (OR $=4.3,95 \%$ CI: 1.9-9.1, $P<0.001)$, table 3 .

\section{Discussion}

This study revealed that maternal anaemia is severe problem in Kassala. According to the World Health Organization, a severe public health problem exists if the prevalence of anaemia is $\geq 40 \%$ in any group [1]. Our data demonstrate a need to re-evaluate or strengthen the current strategies to decrease the prevalence of anaemia among women of reproductive age in this setting. Anaemia has previously been found to affect pregnant women in eastern Sudan regardless of their age and parity [17], which is confirmed in this study. Our data showed that women with severe anaemia were less educated, and had a lower rate of antenatal attendance and a higher rate of rural residency. We also recently observed an association between education level and antenatal care, and an influence of both education and antenatal care on maternal mortality [15].

In the current study, women with severe anaemia had a 3.6 times higher risk of preeclampsia than women with no anaemia. It was recently observed that 17 $(17.7 \%)$ of 97 women with severe anaemia had gestational hypertension or preeclampsia and 2 (2.1\%) had eclampsia [10]. However, it might be difficult to reach a firm conclusion from this report since the authors did not mention the incidence of these events in women with mild/moderate anaemia or with no anaemia. The susceptibility of women with severe anaemia to preeclampsia could be explained by a deficiency of micronutrients and antioxidants. Recent results indicate that reduction in serum levels of calcium, magnesium and zinc during pregnancy might be possible contributors to the development of preeclampsia [18]. We have recently observed a high prevalence of both anaemia (including severe anaemia) and micronutrient deficiency in the same hospital [16]. It might be difficult to determine if severe anaemia was the cause or effect of preeclampsia/ eclampsia in this study as the anaemia was diagnosed at admission and may have been a consequence of the disease process (haemolysis in HELLP syndrome). A longitudinal study with a large sample size is needed to explore whether severe anaemia is a cause or effect of preeclampsia. There may, however, be ethical issues with such a study as severe anaemia is a medical emergency which should be prevented and treated immediately. Poor maternal and perinatal outcomes in cases of anaemia associated with malaria have recently been documented in some regions of Sudan including Kassala [19]. It appears probable that the severe anaemia caused by malaria is a major factor in those outcomes. Previous

Table 2 Maternal and perinatal outcomes in the investigated women*

\begin{tabular}{lllll}
\hline Variable & $\begin{array}{l}\text { non-anaemic } \\
(\mathbf{N}=\mathbf{3 0 3})\end{array}$ & $\begin{array}{l}\text { mild/moderate anaemia } \\
\mathbf{( N = 3 0 3 )}\end{array}$ & $\begin{array}{l}\text { severe anaemia } \\
(\mathbf{N}=\mathbf{3 0 3})\end{array}$ & $\mathbf{P}$ \\
\hline Preeclampsia & $7(2.3 \%)$ & $14(4.6 \%)$ & $25(8.2)$ & 0.004 \\
Eclampsia & $2(0.7 \%)$ & $4(1.3 \%)$ & $10(3.3 \%)$ & 0.03 \\
Preterm birth & $7(2.3)$ & $11(3.6)$ & $35(11.5)$ & $<0.001$ \\
low birth weight & $10(3.3 \%)$ & $23(7.5)$ & $63(20.7)$ & $<0.001$ \\
Stillbirth & $9(2.9)$ & $21(6.9)$ & $42(13.8)$ & $<0.001$ \\
\hline
\end{tabular}

*Data were shown as $\mathrm{n}(\%)$ and the $P$ value is for $\mathrm{X}^{2}$ test comparing the proportions in the subgroups. 
Table 3 Corrected odds ratio and $95 \%$ confidence interval for anaemia and pregnancy outcome in Kassala Hospital, Eastern Sudan

\begin{tabular}{lll}
\hline Variables & Mild/moderate anaemia & Severe anaemia \\
\hline \multirow{2}{*}{ Preeclampsia } & OR $(\mathbf{9 5} \% \mathrm{CI}), \boldsymbol{P}$ & OR $(\mathbf{9 5} \% \mathrm{CI}), \boldsymbol{P}$ \\
\cline { 2 - 3 } Eclampsia & $1.6(0.8-3.4), 0.1$ & $3.6(1.4-9.1), 0.007$ \\
Preterm delivery & $3.2(1.5-6.6), 0.001$ & $4.0(0.7-20.9), 0.09$ \\
Low birth weight & $2.5(1.1-5.7), 0.02$ & $6.6(2.7-16.3),<0.001$ \\
Stillbirth & $1.8(0.7-4.4), 0.1$ & $8.0(3.8-16.0),<0.001$ \\
\hline
\end{tabular}

studies have indicated that malaria increases the risk of hypertensive disorder during pregnancy [20]. Placental histology is the gold standard for the diagnosis of malaria during pregnancy, and is preferred over the peripheral blood film, which has many abnormalities in this setting [21].

Interestingly, earlier studies have reported a higher incidence of preeclampsia and an increased incidence of hypertensive disorders in women with high Hb levels $(13.3 \mathrm{~g} / \mathrm{dl}$ and $12.5 \mathrm{~g} / \mathrm{dl})$ than in those with normal levels [22,23]. Murphy et al. (1986) reported that, in primiparas, the frequency of hypertension ranged from $7 \%$ with $\mathrm{Hb}<10.5 \mathrm{~g} / \mathrm{dl}$ to $42 \%$ with $\mathrm{Hb}>14.5 \mathrm{~g} / \mathrm{dl}$ [24]. The increased incidence of preeclampsia in pregnant women with high $\mathrm{Hb}$ levels could be explained by the toxic effects of methaemoglobin-derived haeme deposition on the vascular endothelium and consequent atherosclerosis [24,25]. Atherosclerotic blood vessels were commonly seen in the placental beds of preeclamptic pregnancies $[25,26]$.

The risk of preterm birth, LBW and stillbirth was higher in anaemic women, and increased with the severity of anaemia. This supports previous observations from Sudan as well as from other African countries $[5,7,8]$. LBW is one of the major causes of the 4 million neonatal deaths per year in developing countries. Neonatal deaths account for $38 \%$ of child deaths under the age of 5 years [27]. If the Millennium Development Goal to reduce the number of child deaths under the age of 5 years by two-thirds by 2015 is to be achieved, a substantial reduction in neonatal deaths is required. Reducing the incidence of LBW births is thus vital, and addressing maternal nutrition to prevent anaemia may a useful strategy in this setting $[1,5]$.

One of the limitations of this study is the difficulty in dissecting preterm birth and LBW. It is difficult and inaccurate to draw conclusions regarding preterm birth and LBW when gestational age is based on the last menstrual period. LBW is highly correlated with gestational age at delivery and both are also correlated with other pregnancy complications such as preeclampsia. It is therefore difficult to draw conclusions regarding these complications when there are no data on gestational age at delivery and whether the preterm delivery was induced (as in preeclampsia/eclampsia) or spontaneous. The other limitation of this study is the weakness of retrospective methods of data collection with respect to the quality of records, the availability of comprehensive records and recollection bias.

\section{Conclusions}

The greater the severity of the anaemia in pregnancy, the greater the risk of preeclampsia, preterm delivery, LBW and stillbirth. Preventive measures should be undertaken to decrease the prevalence of anaemia in pregnancy.

\section{Acknowledgements}

We are very grateful to the Kassala Hospital staff that assisted with data retrieval.

Funding

This work was funded by The National Fund for Promotion of Medical Service, Khartoum, Sudan.

\section{Author details}

${ }^{1}$ Faculty of Medicine, Kassala University, Kassala, Sudan. ${ }^{2}$ Faculty of Medicine, University of Khartoum, Khartoum, Sudan.

\section{Authors' contributions}

AAA, DER and IA undertook the data collection and participated in the statistical analysis. TMA and MIE coordinated the study and participated in study design, statistical analysis and drafting of the manuscript. All authors read and approved the final version. AAA and IA are the guarantors for the paper.

\section{Competing interests}

The authors declare that they have no competing interests.

Received: 20 May 2011 Accepted: 26 August 2011

Published: 26 August 2011

\section{References}

1. De Benoist B, McLean E, Egli I, Cogswell M: Worldwide Prevalence of anaemia 1993-2005: WHO Global Database on Anaemia. Geneva: World Health Organization; 2008.

2. World Health Organization: Antiretroviral Drugs for Treating Pregnant Women and Preventing HIV Infections in Infants: Towards Universal Access: Recommendations for a Public Health Approach. WHO, Geneva; 2006.

3. World Health Organization: The prevalence of anemia in women: a tabulation of available information. Geneva, Switzerland: WHO; 1992

4. Allen LH: Anaemia and iron deficiency: effects on pregnancy outcome. Am J Clin Nutr 2000, 71(Suppl):1280S-1284S.

5. Adam I, Babiker S, Mohmmed A, Salih M, Prins M, Zaki Z: Low body mass index, anaemia and poor perinatal outcome in a rural hospital in eastern Sudan. J Trop Pediatr 2007, 54:202-204.

6. Elhassan EM, Abbaker AO, Haggaz AD, Abubaker MS, Adam I: Anaemia and low birth weight in Medani, Hospital Sudan. BMC Res Notes 2010, 28:181.

7. Haggaz AD, Radi EA, Adam I: Anaemia and low birth weight in Western Sudan. Trans R Soc Trop Med Hyg 2010, 104:234-236.

8. Kidanto HL, Mogren I, Lindmark G, Massawe S, Nystrom L: Risks for preterm delivery and low birth weight are independently increased by severity of maternal anaemia. S Afr Med J 2009, 99(2):98-102.

9. Ali AA, Adam I: Anaemia and stillbirth in Kassala hospital, eastern Sudan. J Trop Pediatr 2011, 57(1):62-4.

10. Rohilla M, Raveendran A, Dhaliwal LK, Chopra S: Severe anaemia in pregnancy: a tertiary hospital experience from northern India. J Obstet Gynaecol 2010, 30(7):694-6. 
11. Levy A, Fraser D, Katz M, Mazor M, Sheiner E: Maternal anemia during pregnancy is an independent risk factor for low birth weight and preterm delivery. Eur J Obstet Gynecol Reprod Biol 2005, 122(2):182-6.

12. Xiong $X$, Buekens $P$, Alexander S, Demianczuk N, Wollast E: Anaemia during pregnancy and birth outcome: A meta-analysis. Am J Perinatol 2000, 17(3):137-146.

13. Bondevik GT, Lie RT, Ulstein M, Kvale G: Maternal hematological status and risk of low birth weight and preterm delivery in Nepal. Acta Obstet Gynecol Scand 2001, 80(5):402-408.

14. Ali AA, Khojali A, Okud A, Adam GK, Adam I: Maternal near-miss in a rural hospital in Sudan. BMC Pregnancy Childbirth 2011, 29:11-48.

15. Ali AA, Adam I: Lack of antenatal care, education, and high maternal mortality in Kassala hospital, eastern Sudan during 2005-2009. J Matern Fetal Neonatal Med 2011, 24(8):1077-1078.

16. Mohamed AA, Ali AA, Ali NI, Abusalama EH, Elbashir MI, Adam I: Zinc, parity, infection and severe anaemia among pregnant women in Kassala, eastern Sudan. Biol Trace Elem Res 2010, 137(3):225-230.

17. Adam I, Khamis AH, Elbashir Ml: Prevalence and risk factors for anaemia in pregnant women of eastern Sudan. Trans R Soc Trop Med Hyg 2005, 99:739-743.

18. Jain S, Sharma P, Kulshreshtha S, Mohan G, Singh S: The role of calcium, magnesium, and zinc in pre-eclampsia. Biol Trace Elem Res 2010, 133(2):162-70.

19. Adam I, Elhassan EM, Haggaz AD, Ali AA, Adam GK: Apprespective of the pidemiology of malaria and anemia and their impact on maternal and perinatal outcomes in different regions of Sudan. J Infec Dev Ctries 2011, 5(2):83-7.

20. Ndao CT, Dumont A, Fievet N, Doucoure S, Gaye A, Lehesran JY: Placental malarial infection as a risk factor for hypertensive disorders during pregnancy in Africa: a case-control study in an urban area of Senegal, West Africa. Am J Epidemiol 2009, 170(7):847-5.

21. Elhassan EM, Haggaz AD, Magzoub MM, Adam I: Non-malarial fever among pregnant women in Medani Hospital, Sudan: Diagnostic uncertainty and overtreatment with quinine. Asian Pac J Trop Med 2010, 5:395-398

22. Huisman A, Aarnoudse JG: Increased 2nd trimester hemoglobin concentration in pregnancies later complicated by hypertension and growth retardation. Early evidence of a reduced plasma volume. Acta Obstet Gynecol Scand 1986, 65:605-8.

23. Phaloprakarn C, Tangjitgamol S: Impact of high maternal hemoglobin at first antenatal visit on pregnancy outcomes: a cohort study. J Perinat Med 2008, 36(2):115-9.

24. Murphy JF, O'Riordan J, Newcombe RG, Coles EC, Pearson JF: Relation of haemoglobin levels in first and second trimesters to outcome of pregnancy. Lancet 1986, 3;1(8488):992-5.

25. Balla G, Vercellotti GM, Muller-Eberhard U, Eaton J, Jacob HS: Exposure of endothelial cells to free heme potentiates damage mediated by granulocyte and toxic oxygen species. Lab Invest 1991, , 64: 648-55.

26. Balla J, Nath K, Balla G, Juckett MB, Jacob HS, Vercellotti GM: Endothelial cell heme oxygenase and ferritin induction in rat lung by hemoglobin in vivo. Am J Physiol 1995, , 268: 321-7.

27. Lawn JE, Cousens S, Zupan J: for the Lancet Neonatal Survival Steering Team (2005) 4 million neonatal deaths: when? where? why? Lancet $365: 891-900$

\section{Submit your next manuscript to BioMed Central and take full advantage of:}

- Convenient online submission

- Thorough peer review

- No space constraints or color figure charges

- Immediate publication on acceptance

- Inclusion in PubMed, CAS, Scopus and Google Scholar

- Research which is freely available for redistribution

Submit your manuscript at www.biomedcentral.com/submit
Biomed Central 